\title{
Application of additive manufacturing in customized titanium mandibular implants for patients with oral tumors
}

\author{
YAN XIA ${ }^{1,2^{*}}$, ZHI CHAO FENG ${ }^{3 *}$, CHANGCHUN LI ${ }^{4}$, HEMING WU ${ }^{1,2}$, \\ CHUNBO TANG $^{1}$, LIHUA WANG ${ }^{5}$ and HONGWEI LI ${ }^{1,2}$ \\ ${ }^{1}$ Jiangsu Key Laboratory of Oral Disease; ${ }^{2}$ Department of Oral and Maxillofacial Surgery, \\ Affiliated Hospital of Stomatology, Nanjing Medical University, Nanjing, Jiangsu 210029, P.R. China; \\ ${ }^{3}$ Rutgers School of Dental Medicine, Rutgers University, Newark, NJ 07103, USA; \\ ${ }^{4}$ Department of Stomatology, The Second Hospital of Nanjing, Nanjing, Jiangsu 210003; \\ ${ }^{5}$ AK Medical Holdings Limited, Beijing 100101, P.R China
}

Received August 25, 2019; Accepted June 18, 2020

DOI: $10.3892 / \mathrm{ol} .2020 .11912$

\begin{abstract}
The application of additive manufacturing (AM) technology has been widely used in various medical fields, including craniomaxillofacial surgery. The aim of the present study was to examine the surgical efficiency and post-operative outcomes of patient-specific titanium mandibular reconstruction using AM. Major steps in directly designing and manufacturing 3D customized titanium implants are discussed. Furthermore, pre-operative preparations, surgical procedures and post-operative treatment outcomes were compared among patients who received mandibular reconstruction using a customized 3D titanium implant, titanium reconstruction plates or vascularized autologous fibular grafting. Use of a customized titanium implant significantly improved surgical efficiency and precision. When compared with mandibular reconstruction using the two conventional approaches, patients who received the customized implant were significantly more satisfied with their facial appearance, and exhibited minimal post-operative complications in the 12-month follow-up period. Patients who underwent mandibular reconstruction using a customized titanium implant displayed improved mandibular contour symmetry, restored occlusal function, normal range of mouth opening and no temporomandibular joint related pain; all complications frequently experienced by patients who undergo conventional approaches of mandibular reconstruction.
\end{abstract}

Correspondence to: Dr Hongwei Li, Department of Oral and Maxillofacial Surgery, Affiliated Hospital of Stomatology, Nanjing Medical University, 136 Hanzhong Road, Nanjing, Jiangsu 210029, P.R. China

E-mail: Hongweili.dentistry@gmail.com

*Contributed equally

Key words: benign tumor of the mandible, oral cancer, personalization, customized titanium implant, Ti6AI4V ELI, titanium plates, vascularized autologous fibular grafting, electron-beam melting

\section{Introduction}

Additive manufacturing (AM) has become integral to modern rapid prototyping. Based on computer-aided design (CAD), AM uses layer-based manufacturing technology to directly produce end products $(1,2)$. In medicine, by utilizing digital slicing of CAD, a 3D scan (generated by Mimics or InVesalius software programs) and microcomputed tomography $(\mu \mathrm{CT})$ data, AM enables direct fabrication of customized biological models for various clinical applications $(3,4)$. These biological models can be used in disease diagnosis, surgical planning, clinical teaching and patient communication $(5,6)$. The process of AM is continuously evolving with advances in the design and manufacturing of customized implants according to patient needs (7). AM provides a bridge that transfers the simulated surgical plan accurately to the surgical site. Therefore, high accuracy, and efficiency in planning and execution of surgical procedures are achieved (8-10). There are $>20$ individual AM processes, which vary in their method of layering and manufacturing $(1,2)$. Among these processes, both selective laser melting and electron-beam melting (EBM) have been extensively developed and improved upon for fabrication of surgical metal implants in various clinical settings $(11,12)$.

Metallic biomaterials, such as 316L stainless steel, cobalt-chromium-based alloy and titanium, have been used extensively in manufacturing of surgical implants (13). In contrast to other biocompatible metals, titanium has improved fatigue resistance and a modulus of elasticity comparable to bone (14). Ti6AI4V extra low interstitial (ELI) is an $\alpha-\beta$ alloy containing $6 \%$ aluminum and $4 \%$ vanadium. Controlled interstitial element levels are designated as an ELI; hence the designation Ti6Al-4V ELI $(15,16)$. Ti6Al-4V ELI is one of the most widely used titanium alloys in the production of surgical implants (17). A previous study has shown that Ti6AI4V ELI exhibits a number of advantages compared with pure titanium, including higher tensile strength and improved fatigue resistance (14). Furthermore, Ti6AI4V ELI has improved tensile strength, suitable stiffness, a high degree of resistance to corrosion and an enhanced porous structure that possesses excellent mechanical properties similar to those of human 
bone (18). Considerable research efforts have been undertaken to evaluate the biocompatibility of Ti6AI4V ELI using EBM (Ti6AI4V ELI EBM) in the physiological environment $(19,20)$. Ti6AI4V ELI EBM exhibits promise for fabrication of hip joints and knee joints for use clinically $(21,22)$.

The mandible is the largest bone in the human skull, and it holds the lower teeth in place, assists in mastication and forms the lower jawline (23). The mandible is composed of the body and the ramus, and is located inferior to the maxilla. The body is the horizontally curved portion that creates the lower jawline (24). Mandibular defects caused by inflammation, trauma and maxillofacial tumors can cause dysfunctions in chewing and facial deformities, and may severely affect a patient's quality of life (25). Due to various sizes of defects and the effect of radiation therapy (in case of cancer treatment) on the blood supply of the surrounding tissues, the repair and reconstruction of mandibular defects has always been a challenging task for surgeons (26). With the development of modern medicine, significant progress has been made in the reconstruction of mandibular defects. At present, there are a variety of repair methods, including commercial reconstruction titanium plates (for example the Stryker Leibinger universal system), non-vascularized autogenous bone grafts, pedicled bone grafts and vascularized fibula free grafts $(27,28)$; however, the existing repair methods often do not perfectly restore the continuity and integrity of the mandible, which may result in a second trauma (29). Using digital medical imaging technology and metal 3D printing technology, according to CT scan data of patients, porous titanium alloy bone tissue substitute materials that are similar in shape, size and weight to the bone defect area can be designed and manufactured to achieve personalized repair and reconstruction of bone defects (30). At present, this technology has been applied in the field of hip, knee, spine and skull reconstruction $(31,32)$; however, to the best of our knowledge, there are limited studies reporting its use in oral and maxillofacial defects (33). The present study included 4 patients with individualized titanium alloy implants and the outcomes were compared with 16 patients who received traditional reconstructed titanium plates and vascularized fibula free flaps through a retrospective controlled study. The conclusion of the present study may provide clinicians with a powerful design and manufacturing technique, to improve the availability of implantable mandibular solutions that overcome the shortcomings of typical fixation plate-based treatment options, thereby improving overall patient outcomes.

\section{Materials and methods}

Workflow. The workflow of reconstruction of mandibular discontinuity using AM technology consisted of several stages: i) 3D digital imaging; ii) data transfer; iii) processing and segmentation; iv) evaluation of design; and v) AM model production and evaluation. In the present study, pre-operative preparations, surgical procedures and post-operative treatment outcomes were compared among patients who received mandibular reconstruction using a customized 3D titanium implant, and two other conventional approaches; titanium reconstruction plates and vascularized autologous fibular grafting (Fig. 1).
Selection criteria. The present study included patients with mandibular defects caused by non-malignant tumors. These tumors have a clear invasive pattern and margin, and radical therapy is recommended, which has high immediate cure success rates (34). Furthermore, patients who did not exhibit tumor recurrence within 1 year of surgery and did not receive radiation therapy were also included. Cases with any condition of uncontrolled inflammation were excluded. The surgical outcome in the prospective cohort of patients was compared with the retrospective cohort of patients who received mandibular reconstruction using two other conventional approaches: Titanium plates or vascularized autologous fibular grafting. The same inclusion and exclusion criteria were also applied to the retrospective cohort cases. The surgical pathology database from Stomatological Hospital of Jiangsu was searched for reported cases of benign oral tumors between January 2014 and February 2017. A total of 16 retrospective cases were identified and follow-up time periods were recorded (Table SI). Among these retrospective cases, 6 patients received implantation of titanium plates, and 10 patients received vascularized autologous fibular grafting. All patients underwent mandibular reconstruction, and their patient files containing pre- and post-operative $\mu \mathrm{CT}$ scans were reviewed. All patients were introduced different types of implants including advantages and disadvantages for each type. The treatment was based on the patient's preference after consultation with surgeons.

Written informed consent for participation in the study was obtained from participants according to the policy of the Stomatological Hospital of Jiangsu Ethical Review Board, and the data were anonymized for analysis and research publication. The present study was approved by the Stomatological Hospital of Jiangsu Ethical Review Board (approval no. PJ2016-003-01).

Patient information. A total of 4 patients (mean age, 33 years; age range, 21-50 years) were recruited prospectively at The Affiliated Hospital of Stomatology of Nanjing Medical University (Nanjing, China) between March 2016 and March 2017. The patients included 2 men and 1 woman who developed recurring ameloblastoma, and another woman who was diagnosed with squamous cell carcinoma. According to the classification scheme proposed by Urken et al (35), the 2 males were classified as having a 'RB' mandibular defect, 1 female was classified as having a 'BS' mandibular defect, and the other female was classified as having a 'BSS' mandibular defect. Based on CT scans, the 2 male cases exhibited local invasion in the lower mandibular ridge and the buccal, and the lingual walls were notably resorbed (Fig. 2A and B). The tumors had spread to the anterior mandibular ascending branch and the soft tissue of the posterior molar. The treatment plans included a combination of mandibular segmental resection and reconstruction following tumor removal. In the case of the female patient with recurring ameloblastoma, the tumor had spread to the mandibular canal, and the treatment plan included a mandibular osteotomy preserving the lower mandibular ridge (Fig. 2C). The female case with squamous cell carcinoma involved large segmental defects within the jaw due to invasion by the gingival squamous cell carcinoma (Fig. 2D). No tumor recurrences were observed within 1 year 


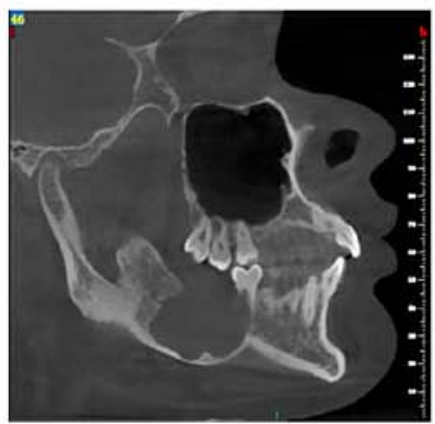

Patient CT scan and images storage in database



Processing of images and 3D model of creation

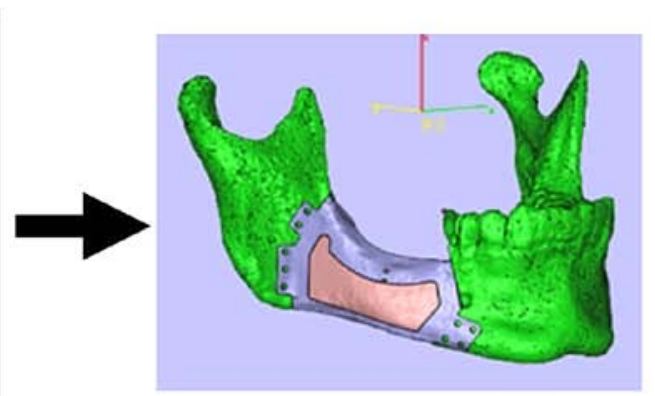

Customized surgery plan and mandible scaffold designs
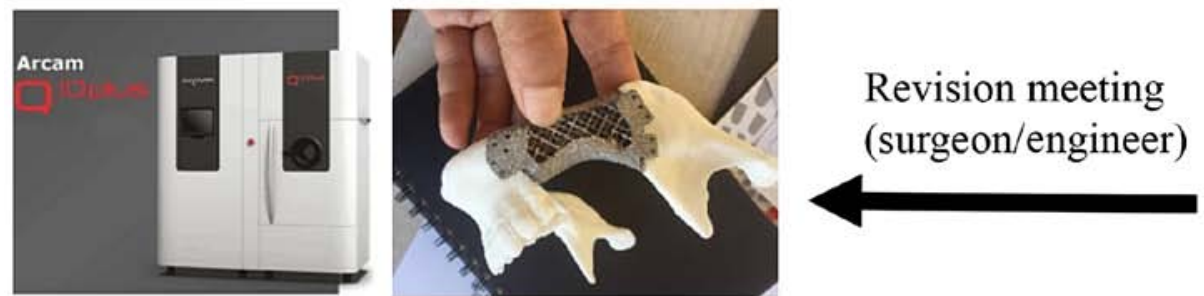

3D printing of titanium scaffold using EBM
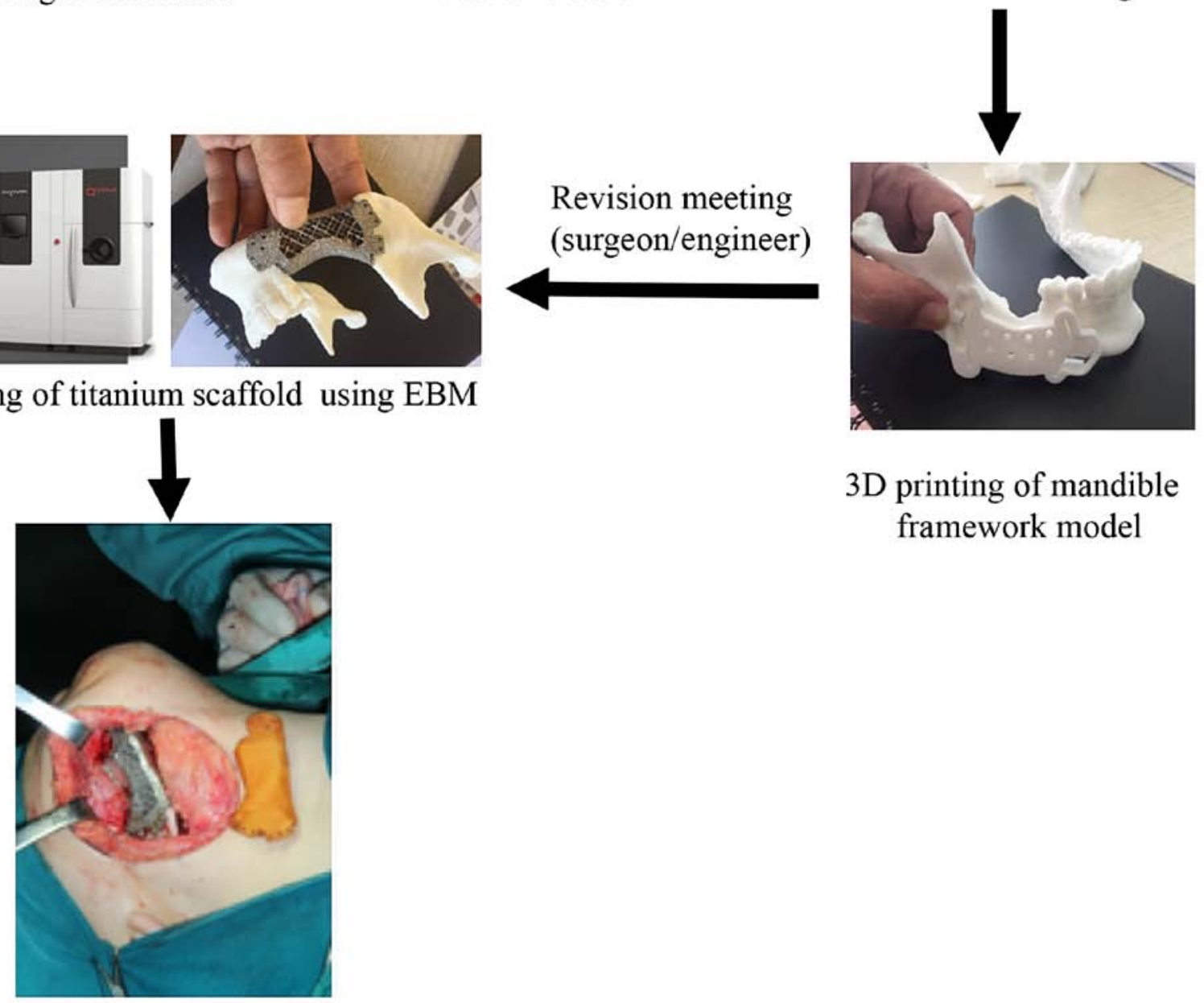

3D printing of mandible framework model

\section{Titanium scaffold sterilization and ready for surgery}

Figure 1. A summary of the workflow for the construction of the complete mandible implant. CT, computed tomography; EBM, electron-beam melting.

after surgery, and therefore this patient was recommended for customized titanium mandibular implantation.

In the present study, the four prospective patients who received customized titanium implants were included in group A (Table SI). Of the remaining cases that were analyzed retrospectively, 6 cases underwent titanium plate implantation and were included in group B, and 10 cases underwent vascularized autologous fibular grafting and were included in group C (Fig. S1 and Table SI). Group B included 3 males and 3 females, and the age range was $18-77$ years, with a mean age of 41.5 years. Group $C$ consisted of 8 males and 2 females, and the age range was 19-65 years, with a mean age of 36.8 years. The breakdown of the benign oral tumor subtypes is presented in Figure S1 nad Table SI. Among all cases, mandibular ameloblastoma was the most common subtype (14 cases), followed by osteofibroma (2 cases), keratocystic odontogenic tumor (2 cases), mandibular cyst (1 case), and squamous cell carcinoma (1 case). The diagnosis of benign oral tumor was confirmed in each case.

$3 D$ medical imaging acquisition. Full 3D digital dental models were obtained using integrating cone-beam computed 
A
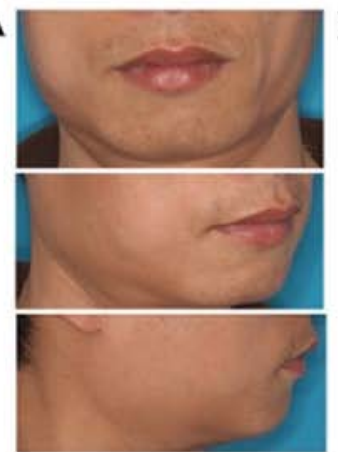

D

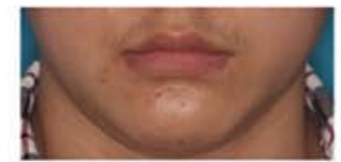

E
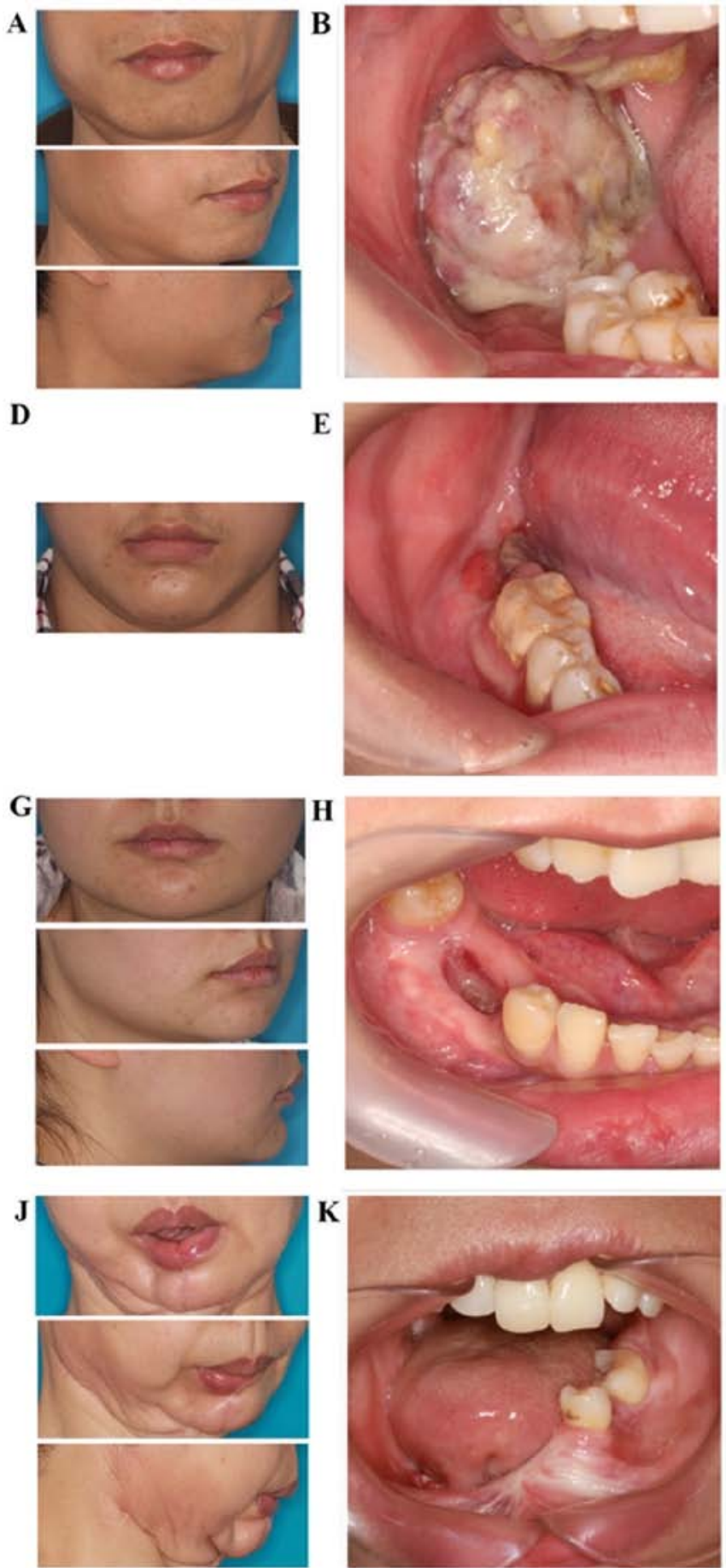
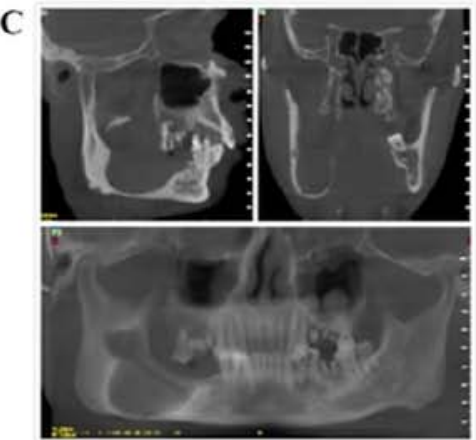

F
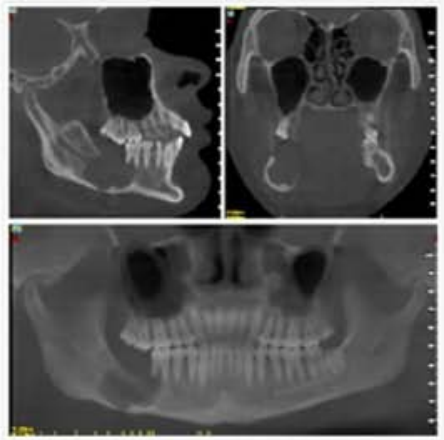

I
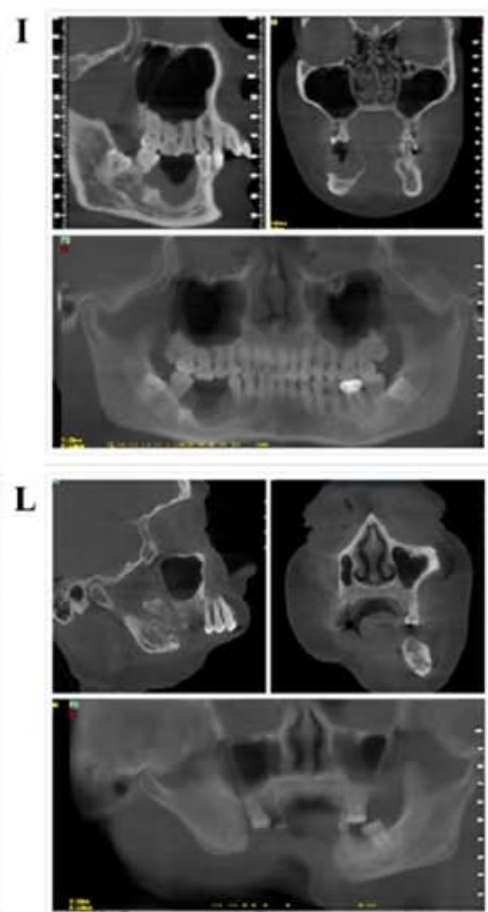

Figure 2. Oral tumor and pre-operative computed tomography images showing mandibular defects for cases 1-4 in group A. (A) Facial appearance, (B) intraoral and (C) panoramic image before surgery in case 1. (D) Facial appearance, (E) intraoral and (F) panoramic image prior to surgery in case 2. (G) Facial appearance, $(\mathrm{H})$ intraoral and (I) panoramic image prior to surgery in case 3. (J) Facial appearance, (K) intraoral and (L) panoramic image prior to surgery in case 4.

tomography (CBCT; NewTom VG, SRL Company). These data were handled, stored and transmitted according to the standards of Digital Imaging and Communications in Medicine (36). The geometric data obtained from the CBCT scans were imported into medical image processing software, including Materialise's interactive medical image control system (Mimics ${ }^{\circledR}$; version 15.0; Materialise) and Analyze ${ }^{\circledR}$ (Mayo Foundation). Using Mimics ${ }^{\circledR}$, a 3D digital anatomical model comprising the patient's mandible was constructed by imaging processing and segmentation. This was followed by construction of a triangular model of bone structure from the volume data by performing a series of computed steps, including region growing, mask formation and 3D model calculation. The anatomical region of mandibular defects was isolated from the entire data, and the selected bone structure was imported and processed using Unigraphics NX (version 10.0; Siemens AG) or Solidworks (version 2014; Dassault Systèmes) for prosthesis design, including refinement of the internal porous structures and the patient-specific 3D mesh structure through topology optimization. The position and 

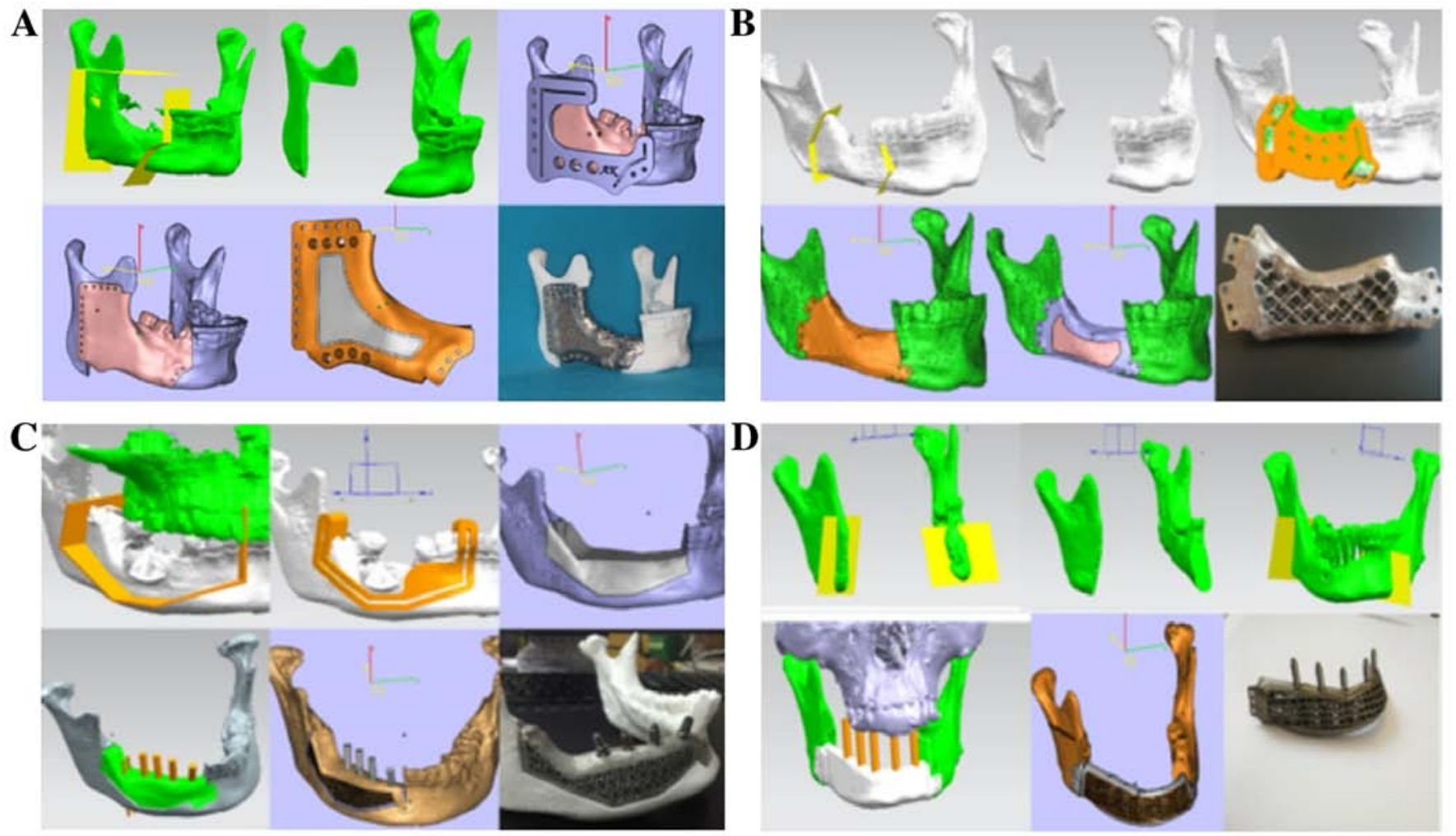

Figure 3. 3D images showing the customized mandibular implant prototype design for cases 1-4 in group A. (A) Case 1, (B) case 2, (C) case 3 and (D) case 4.

model of the personalized implant was designed and determined according to the patient's mandible and occlusion defects. Furthermore, the surgical guide was customized and refined for each reconstruction. After the corresponding stereolithography (STL) file was generated, the obtained STL file was imported into Magics (version 20; Materialize) for data error fixing, positing the part in the build envelop, and for creating the scaffold and slicing. Finally, the corrected STL file was sent for production of implants using Ti6AL4V ELI (Arcam AB; model 2016), which meets the national standards GB/T 13810 of titanium alloy for surgical implants in China. The implants were produced by Beijing Aikang Co., Ltd., and were casted in titanium alloy according to the design of position during printing. (Fig. 3) The entire design and manufacturing process of personalized porous titanium alloy implant took $\sim 3$ weeks.

Surgery. All patients received pre-operative antiseptic oral rinsing and treatment was maintained with intravenous antibiotics (Cefazolin Sodium Pentahydrate Inj Pwd F/Sol; $1 \mathrm{~g}$ ). For patients in group A (Figs. 4 and 5), customized titanium implants were designed using computer-aided software and constructed using an EBM system (37). Prior to surgery, the titanium implants were cleaned using ultrasonic vibration and then sterilized using high temperature steam. During the operation, osteotomy was performed according to the surgical guide, which controlled the position and direction of resection. Segmental resection of the mandible including the benign tumor was removed. After the customized titanium plate was inserted and fixed with 4-8 titanium screws (10-mm; Stryker Leibinger GmbH \& Co.), the oral tissues were stitched back into place using dissolvable stitches. Patients received antibiotics after surgery [Cefoxitin, $1 \mathrm{~g}$, intravenously (i.v.), once a day for 5 days]. For patients in group B, the mandibulectomy area was measured and confirmed based on $\mu \mathrm{CT}$ images. The sterilized titanium reconstruction plate was pre-bent to fit the resected mandible. After the benign tumor was removed, the prebent titanium reconstruction plate was fixed on residual bone using 3-4 titanium screws on each side. Patients received antibiotics after surgery as aforementioned. For patients in group $\mathrm{C}$, the defects were confirmed by $\mu \mathrm{CT}$ scans. A two-team approach was used for the surgery; one team focused on resection of the benign tumor; the other team focused on mandibular reconstruction using vascularized free fibular flap grafting. Harvesting and contouring of the fibula free flap took $\sim 120 \mathrm{~min}$. The modelled fibula flap was placed between the mandibular stumps and fixed to the titanium plate with multiple screws. Finally, the micro-anastomoses were constructed and the skin was sutured into its definitive position. Patients received immediate post-operative special care (Ceftriaxone, $1 \mathrm{~g}$, IV, once a day for 5 days; Ornidazole, $0.5 \mathrm{~g}$, IV, twice a day for 3 days) with anti-inflammatory (dexamethasone sodium phosphate injection, $10 \mathrm{mg}$, i.v., once a day for 3 days) and anti-coagulant medications (hemocoagulase injection, $1 \mathrm{KU}$, intramuscular injection, once a day for 3 days).

Post-operative outcome assessment. The main clinical outcome was evaluated using assessment scale and measures referring to the EORTC QLQ-C30/QLQ-H\&N35 questionnaires $(38,39)$, and the University of Washington Quality of Life questionnaire $(40,41)$. The items related to head and neck tumors were selected, and modified to the specific situation to formulate the prognostic evaluation form (Table SII). The questionnaire contained seven categories: Facial 



Figure 4. Mandibular reconstruction and post-operative computed tomography scans of patient cases 1-4 in group A. (A) Case 1, (B) case 2, (C) case 3 and (D) case 4.
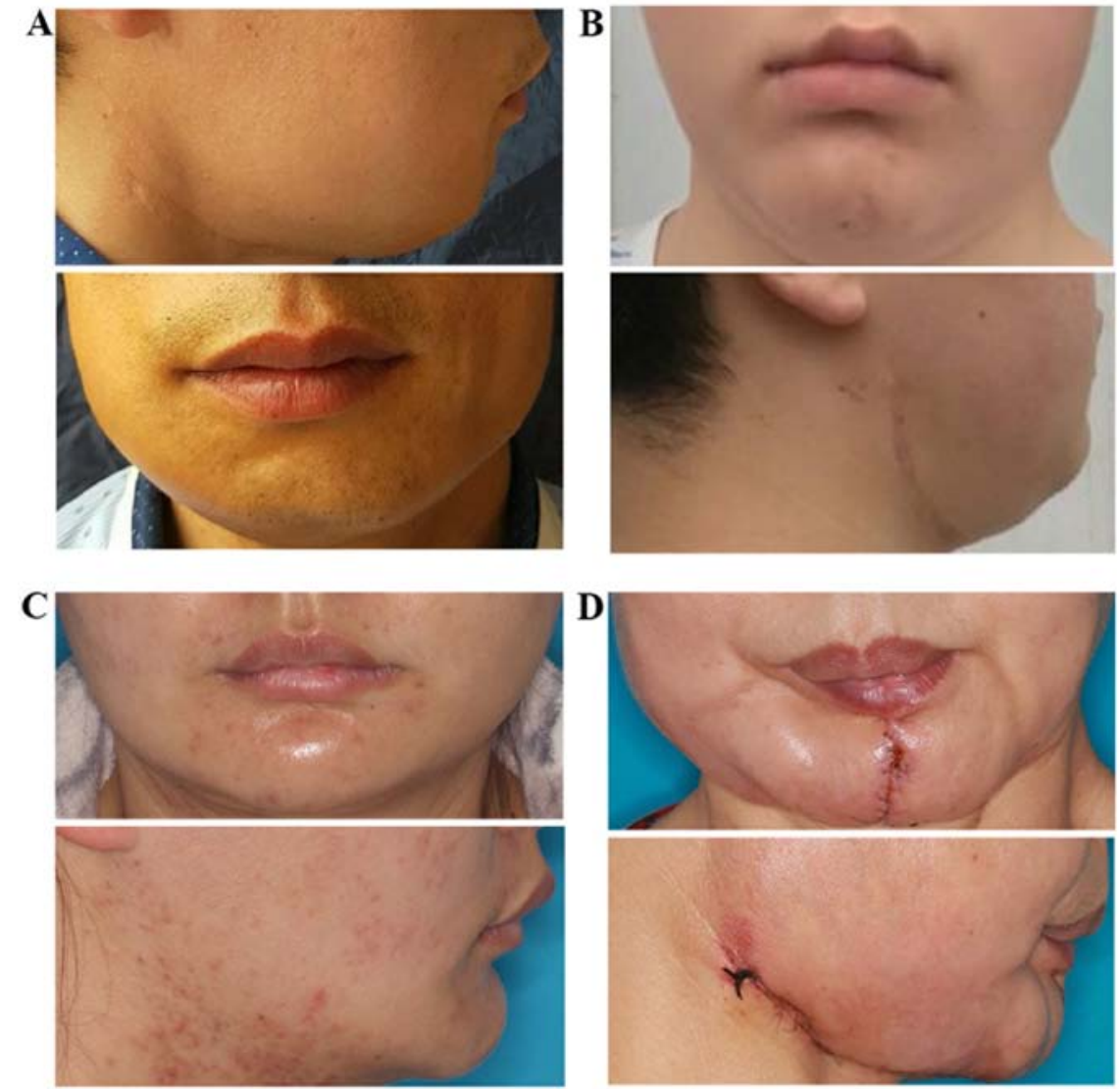

Figure 5. Post-operative recovery of patients in group A. (A) Case 1, (B) case 2, (C) case 3 and (D) case 4. Cases 1-3 had good postoperative dental restoration. Case 4 had a smaller range of maximum opening due to scar formation from a previous operation, but the continuity of the mandibular was restored, and the patient was satisfied with her facial appearance. 
appearance, occlusal force and chewing, pain [as determined by verbal rating scale (42)], opening degree, speech, swallowing/eating and mentality. Each category was given a score. The total score of seven categories ranged between 7-28, and was subsequently divided into 4 grades. Higher scores corresponded to worse symptoms and, consequently, a worse quality of life. The prognosis was classified into one of four grades (grade I-IV). Briefly, grade I (score 7-12) was characterized as satisfied facial appearance, balanced mandibular contour symmetry, normal occlusal force and chewing efficiency, no temporomandibular joint related pain and normal maximum mouth opening. Grade II (score 13-17) was characterized as slightly unilateral facial depression or bulging, restored occlusal function with chewing efficiency of $60-80 \%$, mild temporomandibular joint related pain, two finger mouth opening, and slight difficulty to communicate, eat and socialize. Grade III (score 18-22) was characterized as unilateral facial asymmetry with obvious depression or bulging, implant fracture, reduced occlusal force with chewing efficiency of 40-60\%, one finger mouth opening and a high degree of masticatory difficulty, and difficulty to communicate, eat and socialize. Grade IV (score 23-28) was characterized as extreme facial asymmetry with significant depression or bulging, significantly reduced occlusal force associated with $<40 \%$ chewing efficiency, severe pain, severely limited mouth opening, and considerable difficulty communicating, eating and socializing, implant removal due to post-operative infection, implant loosening and tumor recurrence. Patients with a total score between 7 and 12 were classified as grade I (best outcome); patients with a total score between 13 and 17 were classified as grade II; patients with a score between 18 and 22 were classified as grade III; and patients with a total score of 23 and 28 were classified as grade IV (the worst outcome).

Statistical analysis. Associations between groups were analyzed using SPSS version software 19.0 (IBM Corp.). The post-operative outcomes among group A, B and C were scored according to prognostic evaluation (Table SII) and analyzed using Kruskal-Wallis $\mathrm{H}$ non-parametric test followed by Dunn's test for intergroup comparisons. $\mathrm{P}<0.05$ was considered to indicate a statistically significant difference.

\section{Results}

In group A, mandibular defects were repaired using customized titanium implants in patients. The mean operative time of group A was 130 min (range, 90-160 min), and the mean length of follow-up was 12 months (range, 3-19 months). In group A, all patients had post-operative $\mu \mathrm{CT}$ scans verifying the accuracy of positioning of customized titanium implants and complete tumor removal (Fig. 4). The continuity of the mandible of all 4 patients was restored (Fig. 4). Furthermore, they almost fully recovered the ability to ingest the same foodstuffs they were able to ingest prior to surgery, along with normal maximum mouth opening (25-40 mm) (Fig. 5). Among these 4 patients, 2 males and 1 female had good postoperative dental restoration (Fig. 5). One female (case 4) had a significantly shorter follow-up time. This female patient had a smaller range of maximum opening range due to scar
Table I. Summary and analysis of post-operative outcomes among group $\mathrm{A}, \mathrm{B}$ and $\mathrm{C}$.

Four-grade clinical outcome

\begin{tabular}{lcccc}
\cline { 2 - 5 } Group & I & II & III & IV \\
\hline A & 3 & 1 & 0 & 0 \\
B & 0 & 3 & 2 & 1 \\
C & 1 & 5 & 3 & 1 \\
\hline Total & 4 & 8 & 5 & 2 \\
\hline
\end{tabular}

Table II. Statistical analysis of the post-operative outcomes among groups $\mathrm{A}, \mathrm{B}$ and $\mathrm{C}$.

\begin{tabular}{lccc}
\hline Group & A & B & C \\
\hline B & 0.0191 & NA & NA \\
C & 0.0378 & 0.873 & NA
\end{tabular}

NA, not applicable.

formation from a previous operation, but the continuity of the mandibula was restored, and the patient was satisfied with their facial appearance (Fig. 5). Overall, postoperative dental rehabilitation was completed with satisfactory results in all patients in group A. No tumor recurrences were observed.

According to the criteria on facial appearance, occlusal force and chewing, pain, opening degree, speech, swallowing/eating and mentality, the prognosis was classified into four different grades (Table SII). Group A patients had improved post-operative outcomes compared with both groups B and C (Table I). In group A $(n=4), 3$ patients were grade I and 1 patient was grade II; however, groups B and $C$ rarely obtained a grade I clinical outcome score (Table I). In group $B(n=6), 3$ patients were grade II, 2 patients were grade III and 1 patient was grade IV. In group C $(n=10)$, 1 patient was grade I, 5 patients were grade II, 3 patients were grade III and 1 patient was grade IV. The outcomes among groups A, B and C were analyzed using Kruskal-Wallis $\mathrm{H}$ non-parametric test, which revealed that post-operative treatment outcomes were significantly different among the three groups $(\mathrm{P}=0.033)$. Subsequently, the outcomes were compared between two groups by Dunn's test (Table II). This demonstrated that operative treatment outcomes were significantly different between groups $\mathrm{A}$ and $\mathrm{B}(\mathrm{P}=0.0191)$, and between groups $\mathrm{A}$ and $\mathrm{C}(\mathrm{P}=0.0378)$. However, no significant difference was identified between groups $\mathrm{B}$ and $\mathrm{C}(\mathrm{P}=0.873)$.

In summary, patients who underwent mandibular reconstruction using a customized titanium implant exhibited improved mandibular contour symmetry, restored occlusal function, a normal range of mouth opening and no temporomandibular joint related pain (Table SIII). This was in contrast to the increased risk of unilateral facial asymmetry, limited mouth opening, decreased chewing function as well as implant 
loosening observed in patients who received one of the other two conventional approaches (Table SIII).

\section{Discussion}

The mandible serves a critical role in several physiological aspects, including craniofacial growth and development, mastication, swallowing and breathing (23). Accurate mandibular reconstruction has always been a challenge (43). Mandibular defects may result from radioactive osteonecrosis, trauma, inflammation, oral cavity carcinoma and cysts. The reconstruction of mandibular defects following surgical extirpation of oral cavity carcinoma accounts for $80 \%$ of clinical cases $(40,41)$. The goals of mandibular reconstruction are re-establishment of mandibular continuity and completeness, correction of mandibular deformity and restoration of mandibular functions (44). Current trends in mandibular reconstruction with modern medical applications aim to take into consideration several factors, including accurate reconstruction of the normal anatomy, the degree of occlusion and proper biomechanical compatibility with the surrounding bone tissues (45).

The use of titanium plates in mandibular reconstruction has been widely implemented (46-48). The primary advantages of this approach are: i) Lower-complexity surgical procedures; ii) reduced fatigue of the metal; and iii) improved adaptation of reconstruction plates $(49,50)$. However, disadvantages include, decreased rigidity and fracturing of titanium plates $(51,52)$. Furthermore, if any radiotherapy patient has inadequate soft tissue coverage over the operative site, the individual may be at high-risk for plate protrusion and thus infection, requiring removal of implant and thus surgical failure $(51,53)$. Although titanium plate systems for maxillofacial surgery are currently available from several different manufacturers, the choice of systems from various manufacturers always results in differences in clinical outcome. Several of the placed titanium implants later negatively influence denture repair (54). Autologous bone grafting can be categorized as non-vascularized and vascularized. Non-vascularized autologous bone grafting is less demanding, less invasive and has fewer common complications (55-57). However, the major limitation of this approach is that the implant has no blood supply of its own, which is followed by severe graft resorption. A notable reduction in bony height further complicates predictable implant rehabilitation (58). Furthermore, the bone graft is avascular making it susceptible to delayed union and infection, and may result in permanent damage to soft tissues thereby increasing the chances of failure in patients $(59,60)$. By contrast, vascularized autologous bone grafting overcomes these limitations by virtue of its inherent own vasculature and can be harvested with soft tissues (61). This explains the increased popularity of vascularized autologous bone grafting as the standard option (62). Multiple reconstructive options have emerged for mandibular reconstruction, including iliac crest, rib and fibula (63). The fibula was first utilized by Hidalgo et al (64) for mandibular reconstruction in 1989. Compared with other options, the fibula has gained widespread use, owing to its versatility by offering great length and thickness of bone, intraosseous and segmental blood supply, and reliable skin paddle for simultaneous soft tissue reconstruction $(65,66)$. Therefore, the use of the fibula for mandibular reconstruction is well accepted among numerous oral maxillofacial surgeons (62). However, despite its merits, harvesting and contouring of the fibula demands tremendous skill and expertise. Furthermore, post-operative facial symmetry is an important aesthetic aspect, which is very difficult to achieve (67). Previous studies have reported that harvesting the fibula increases the risk of donor-site morbidity, and lowers walking endurance in the short-term and decrease the ability to do strenuous activity in the long-term $(68,69)$. Certain patients may also experience mild lameness, and the loss of bony height always results in notable challenges to post-operative denture restoration (70). Although there have been some successes, tissue engineering is not yet ready for mandibular reconstruction in terms of clinical outcomes. Current obstacles remain to develop an ideal biocompatible bone repair scaffold that possesses suitable microstructure. Natural biological materials, such as chitosan-fibrin and hydroxyapatite, possess excellent cell adhesion and growth support properties $(71,72)$. However, these polymers lack mechanical strength and physical stability, which limit their application in reconstruction of load-bearing areas of the mandible, and are thus likely to result in the implant failure (70).

Recent advances in digital imaging and CAD have made it possible to create customized 3D models from medical images (73). AM technology, also known as 3D printing, allows the use of patient-specific digital models to manufacture anatomically-specific 3D mesh titanium scaffolds for the reconstruction of mandibular defects (74). AM technology offers a new level of control over the architecture of porosity and hardness of titanium to match the Young's modulus to that of the bone tissue. As a result, the resulting titanium product has improved stress-shielding effects, which may stimulate osteogenesis, thereby significantly enhancing implant-bone interface stability and reducing the risk of implant loosening (75). Furthermore, titanium with microporous structure allows better cell adhesion and increased bone in-growth to achieve biological fixation (76). $3 \mathrm{D}$ printing can build complex porous features inside the implant to enhance biocompatibility (77), and allows the clinician the capability to design these implants to aesthetically enhance the cosmetic outcome. Indeed, improved post-operative denture restoration was observed in patients with customized mandibular implants in the present study. When compared with other conventional approaches, the operative time was reduced. Among all the treatment groups, group A were the most satisfied in regard to their facial symmetry, and exhibited the most improved maximum mouth opening and occlusal function. Furthermore, high-precision 3D printed titanium alloy implants can be quickly positioned and fixed during surgery, instead of applying traditional finished reconstructed titanium plates to repair, it takes less time during the operation to bend to fit the mandible ends and restore maxillofacial appearance. Overall, in contrast to other treatment options, patients who received the customized titanium implant showed improved post-operative life quality.

The strength of AM technology lies in the areas where traditional implantation approaches are limited, including personalization. However, customized implants should be designed with exacting parameters, which require highresolution imaging techniques to optimize the bone-to-implant interface. The design and manufacture of high-quality customized implants for mandibular reconstruction are complicated, and require close collaboration between clinicians and 
engineers. Although the use of AM technology in mandibular reconstruction is promising, the widespread application of this technology is limited by several important factors, including i) Costly materials and equipment maintenance; ii) sub-optimal porous structure and mechanical performance; iii) available techniques for implant surface modification; and iv) low resistance to clinically relevant cumulative radiation doses in patients with malignant tumors (78).

In conclusion, 3D printing has been applied in the medical field, including in complex surgical procedure design, surgical simulation, surgical guide fabrication, implant design and manufacturing (79). For the reconstruction of mandibular defects, treatment options include reconstruction of titanium plates and vascularized autologous bone grafts, but each method has its advantages and disadvantages (80). With advances in 3D printing technology, it has become possible to manufacture custom titanium implants for mandibular reconstruction. By obtaining digital image data of patients through CT scans, it is possible to construct 3D models, optimize surgical schemes, design and manufacture custom titanium alloy implants, improve the accuracy of the surgical procedure, reduce the operation time and improve the effect of repair and reconstruction (81). Advancements in AM technology within oral and maxillofacial surgery are positively affecting the health of these patients. The present study has elucidated a detailed approach of using customized titanium implants for reconstruction of mandibular defects. Patients with customized titanium implants exhibited improved mandibular contour symmetry and functions, with minimum post-operative complications. Taken together, the present study has provided a more detailed picture of development of customized implants. This will aid future studies to take a more efficient and feasible route to the manufacture of such products in order to achieve the implant's desired outcomes and complexity. Based on the results of the present study, surgeons may be able to formulate adequate strategies and contingency plans to control post-operative complications. Notably, this work will lead to heightened confidence in this emerging AM technology for its application in oral and maxillofacial surgery.

\section{Acknowledgements}

Not applicable.

\section{Funding}

This work was supported by the Priority Academic Program Development of Jiangsu Higher Education Institutions (grant no. ZCB2012010).

\section{Availability of data and materials}

The datasets used and/or analyzed during the present study are available from the corresponding author on reasonable request.

\section{Authors' contributions}

YX and HL contributed to the conception, design and data acquisition. YX, ZCF, CL and HL contributed to data analysis and interpretation, and drafted and critically revised the manuscript. HW, CT and LW contributed to data acquisition and analysis, and critically revised the manuscript. All authors read and approved the final manuscript.

\section{Ethics approval and consent to participate}

Written informed consent for participation in the study was obtained from participants according to the policy of the Stomatological Hospital of Jiangsu Ethical Review Board, and the data were anonymized for analysis and research publication. The present study was approved by the Stomatological Hospital of Jiangsu Ethical Review Board (approval no. PJ2016-003-01).

\section{Patient consent for publication}

Participants provided informed consent for publication of identifying information/images in an online publication.

\section{Competing interests}

The authors declare that they have no competing interests.

\section{References}

1. Jiménez M,Romero L,Domínguez I,Espinosa M and Domínguez M: Additive Manufacturing Technologies: An Overview about 3D Printing Methods and Future Prospects. Complexity 2019: 30, 2019.

2. Berman B: 3-D printing: The new industrial revolution. Bussiness Horizons 55: 155-162, 2012.

3. Truscott M, Beer D, Vicatos G, Hosking K, Barnard L, Booysen G and Ian Campbell R: Using RP to promote collaborative design of customised medical implants. Rapid Prototyping J 13: 8, 2007.

4. Khan SF and Dalgarno KW: Design of customised bioceramic medical implants by layered manufacturing, 2009.

5. Rodby KA, Turin S, Jacobs RJ, Cruz JF, Hassid VJ, Kolokythas A and Antony AK: Advances in oncologic head and neck reconstruction: Systematic review and future considerations of virtual surgical planning and computer aided design/computer aided modeling. J Plast Reconstr Aesthet Surg 67: 1171-1185, 2014.

6. Rengier F, Mehndiratta A, von Tengg-Kobligk H, Zechmann CM, Unterhinninghofen R, Kauczor HU and Giesel FL: 3D printing based on imaging data: Review of medical applications. Int $\mathbf{J}$ Comput Assist Radiol Surg 5: 335-341, 2010.

7. Tack P, Victor J, Gemmel P and Annemans L: 3D-printing techniques in a medical setting: A systematic literature review. Biomed Eng Online 15: 115, 2016.

8. Salmi M, Tuomi J, Paloheimo KS, Björkstrand R, Paloheimo M, Salo J, Kontio R, Mesimäki K and Mäkitie A: Patient-specific reconstruction with 3D modeling and DMLS additive manufacturing. Rapid Prototyp J 18: 209-214, 2012

9. Philippe B: Custom-made prefabricated titanium miniplates in Le Fort I osteotomies: Principles, procedure and clinical insights. Int J Oral Maxillofac Surg 42: 1001-1006, 2013.

10. Zeng C, Xing W, Wu Z, Huang $\mathrm{H}$ and Huang W: A combination of three-dimensional printing and computer-assisted virtual surgical procedure for preoperative planning of acetabular fracture reduction. Injury 47: 2223-2227, 2016.

11. Prochor $\mathrm{P}$ and Mierzejewska ZA: Influence of the surface roughness of PEEK GRF30 and Ti6A14V SLM on the viability of primary human osteoblasts determined by the MTT Test. Materials (Basel) 12: 4189, 2019.

12. Vaezi M, Drescher P and Seitz H: Beamless metal additive manufacturing. Materials (Basel) 13: 922, 2020.

13. Chen Q and Thouas GA: Metallic implant biomaterials. Materials Science Engineering 87: 1-57, 2015.

14. Vandenbroucke B and Kruth JP: Selective laser melting of biocompatible metals for rapid manufacturing of medical parts. Rapid Prototyp J 13: 196-203, 2007.

15. Zhou C, Lei F, Chodosh J and Paschalis EI: The role of titanium surface microtopography on adhesion, proliferation, transformation, and matrix deposition of corneal cells. Invest Ophthalmol Vis Sci 57: 1927-1938, 2016. 
16. Traini T, Mangano C, Sammons RL, Mangano F, Macchi A and Piattelli A: Direct laser metal sintering as a new approach to fabrication of an isoelastic functionally graded material for manufacture of porous titanium dental implants. Dent Mater 24: 1525-1533, 2008.

17. Abdelrhman Y, Gepreel MA, Kobayashi S, Okano S and Okamoto T: Biocompatibility of new low-cost $(\alpha+\beta)$-type Ti-Mo-Fe alloys for long-term implantation. Mater Sci Eng C Mater Biol Appl 99: 552-562, 2019.

18. Ponader S, von Wilmowsky C, Widenmayer M, Lutz R, Heinl P, Körner C, Singer RF, Nkenke E, Neukam FW and Schlegel KA In vivo performance of selective electron beam-melted Ti-6Al-4V structures. J Biomed Mater Res A 92: 56-62, 2010

19. Parthasarathy J, Starly B, Raman S and Christensen A: Mechanical evaluation of porous titanium (Ti6A14V) structures with electron beam melting (EBM). J Mech Behav Biomed Mater 3: 249-259, 2010.

20. Murr LE, Amato KN, Li SJ, Tian YX, Cheng XY, Gaytan SM, Martinez E, Shindo PW, Medina F and Wicker RB: Microstructure and mechanical properties of open-cellular biomaterials prototypes for total knee replacement implants fabricated by electron beam melting. J Mech Behav Biomed Mater 4: 1396-1411, 2011.

21. Cronskär M,Rännar LE and Bäckström M: Production of Customized Hip Stem Prostheses: A Comparison Between Machining and Additive Manufacturing. Rapid Prototyp J 19: 365-372, 2011.

22. Jardini AL, Larosa MA, Maciel Filho R, Zavaglia CA, Bernardes LF, Lambert CS, Calderoni DR and Kharmandayan P: Cranial reconstruction: 3D biomodel and custom-built implant created using additive manufacturing. J Craniomaxillofac Surg 42: 1877-1884, 2014

23. Breeland G, Aktar A and Patel BC: Anatomy, Head and Neck, Mandible. In: StatPearls, Treasure Island (FL), 2020.

24. Zhang J, Liu M, Wang L, Chen S, Yuan P, Li J, Shen SG, Tang Z, Chen KC, Xia JJ and Shen D: Context-guided fully convolutional networks for joint craniomaxillofacial bone segmentation and landmark digitization. Med Image Anal 60: 101621, 2020.

25. Lee S, Choi D, Shim JH and Nam W: Efficacy of threedimensionally printed polycaprolactone/beta tricalcium phosphate scaffold on mandibular reconstruction. Sci Rep 10: 4979, 2020.

26. Alfotawi R and Ayoub A: Reconstruction of maxillofacial bone defects: Contemporary methods and future techniques. Am J Adv Med Sci 2: 18-27, 2014.

27. Ansari E, Chargi N, van Gemert JTM, van Es RJJ, Dieleman FJ, Rosenberg AJWP, Van Cann EM and de Bree R: Low skeletal muscle mass is a strong predictive factor for surgical complications and a prognostic factor in oral cancer patients undergoing mandibular reconstruction with a free fibula flap. Oral Oncol 101 104530, 2020.

28. Mesgarzadeh AH, Abadi A and Keshani F: Seven-year follow-up of spontaneous bone regeneration following segmental mandibulectomy: Alternative option for mandibular reconstruction. Dent Res J (Isfahan) 16: 435-440, 2019.

29. Tatara AM, Koons GL, Watson E, Piepergerdes TC, Shah SR Smith BT, Shum J, Melville JC, Hanna IA, Demian N, et al: Biomaterials-aided mandibular reconstruction using in vivo bioreactors. Proc Natl Acad Sci USA 116: 6954-6963, 2019

30. Zhang M, Lin R, Wang X, Xue J, Deng C, Feng C, Zhuang H, Ma J, Qin C, Wan L, et al: 3D printing of Haversian bone-mimicking scaffolds for multicellular delivery in bone regeneration. Sci Adv 6: eaaz6725, 2020.

31. Tsukamoto Y, Akagi T and Akashi M: Vascularized cardiac tissue construction with orientation by layer-by-layer method and 3D printer. Sci Rep 10: 5484, 2020.

32. Belaid H, Nagarajan S, Teyssier C, Barou C, Barés J, Balme S, Garay $\mathrm{H}$, Huon V, Cornu D, Cavaillès $\mathrm{V}$ and Bechelany $\mathrm{M}$ : Development of new biocompatible 3D printed graphene oxide-based scaffolds. Mater Sci Eng C Mater Biol Appl 110: 110595, 2020.

33. Pacifici A, Polimeni A and Pacifici L: Additive manufacturing and biomimetic materials in oral and maxillofacial surgery: A topical overview. J Biol Regul Homeost Agents 32: 1579-1582, 2018.

34. Rink B: Mandibular resection in cancer of the tongue and/or mouth floor. HNO 39: 224-226, 1991 (In German).

35. Urken ML, Weinberg H, Vickery C, Buchbinder D, Lawson W and Biller HF: Oromandibular reconstruction using microvascular composite free flaps. Report of 71 cases and a new classification scheme for bony, soft-tissue, and neurologic defects. Arch Otolaryngol Head Neck Surg 117: 733-744, 1991

36. Burgess J: Digital DICOM in dentistry. Open Dent J 9: 330-336, 2015

37. Parthasarathy J: 3D modeling, custom implants and its future perspectives in craniofacial surgery. Ann Maxillofac Surg 4: 9-18, 2014
38. Wan Leung S, Lee TF, Chien CY, Chao PJ, Tsai WL and Fang FM: Health-related quality of life in 640 head and neck cancer survivors after radiotherapy using EORTC QLQ-C30 and QLQ-H\&N35 questionnaires. BMC Cancer 11: 128, 2011.

39. Tschudi D, Stoeckli S and Schmid S: Quality of life after different treatment modalities for carcinoma of the oropharynx. Laryngoscope 113: 1949-1954, 2003

40. Boyapati RP, Shah KC, Flood V and Stassen LF: Quality of life outcome measures using UW-QOL questionnaire v4 in early oral cancer/squamous cell cancer resections of the tongue and floor of mouth with reconstruction solely using local methods. Br J Oral Maxillofac Surg 51: 502-507, 2013.

41. Viana TSA, Silva PGB, Pereira KMA, Mota MRL, Alves APNN, de Souza EF and Sousa FB: Prospective evaluation of quality of life in patients undergoing primary surgery for oral cancer: Preoperative and postoperative analysis. Asian Pac J Cancer Prev 18: 2093-2100, 2017.

42. Williamson A and Hoggart B: Pain: A review of three commonly used pain rating scales. J Clin Nurs 14: 798-804, 2005.

43. Dimitroulis G: Mandibular reconstruction following ablative tumour surgery: An overview of treatment planning. Aust N Z J Surg 70: 120-126, 2000

44. Bak M, Jacobson AS, Buchbinder D and Urken ML: Contemporary reconstruction of the mandible. Oral Oncol 46: 71-76, 2010

45. Zhang M, Rao P, Xia D, Sun L, Cai X and Xiao J: Functional reconstruction of mandibular segment defects with individual preformed reconstruction plate and computed tomographic angiography-aided iliac crest flap. J Oral Maxillofac Surg 77: 1293-1304, 2019.

46. Kumar BP, Venkatesh V, Kumar KA, Yadav BY and Mohan SR: Mandibular Reconstruction: Overview. J Maxillofac Oral Surg 15: 425-441, 2016

47. Bowerman JE: A review of reconstruction of the mandible. Proc R Soc Med 67: 610-614, 1974

48. Gullane PJ and Holmes H: Mandibular reconstruction. New concepts. Arch Otolaryngol Head Neck Surg 112: 714-719, 1986.

49. Schusterman MA, Reece GP, Kroll SS and Weldon ME: Use of the AO plate for immediate mandibular reconstruction in cancer patients. Plast Reconstr Surg 88: 588-593, 1991

50. Vuillemin T, Raveh J and Sutter F: Mandibular reconstruction with the titanium hollow screw reconstruction plate (THORP) system: evaluation of 62 cases. Plast Reconstr Surg 82: 804-814, 1988.

51. Liu YF, Xu LW, Zhu HY and Liu SS: Technical procedures for template-guided surgery for mandibular reconstruction based on digital design and manufacturing. Biomed Eng Online 13: 63 , 2014

52. Wikesjo UM, Susin C, Qahash M, Polimeni G, Leknes KN, Shanaman RH, Prasad HS, Rohrer MD and Hall J: The critical-size supraalveolar peri-implant defect model: Characteristics and use. J Clin Periodontol 33: 846-854, 2006.

53. Sadr-Eshkevari P, Rashad A, Vahdati SA, Garajei A, Bohluli B and Maurer P: Alloplastic mandibular reconstruction: A systematic review and meta-analysis of the current century case series. Plast Reconstr Surg 132: 413e-427e, 2013.

54. Shibahara T, Noma H, Furuya Y and Takaki R: Fracture of mandibular reconstruction plates used after tumor resection. J Oral Maxillofac Surg 60: 182-185, 2002.

55. Gadre PK, Ramanojam S, Patankar A and Gadre KS Nonvascularized bone grafting for mandibular reconstruction: Myth or reality? J Craniofac Surg 22: 1727-1735, 2011

56. Handschel J, Hassanyar H, Depprich RA, Ommerborn MA, Sproll KC, Hofer M, Kübler NR and Naujoks C: Nonvascularized iliac bone grafts for mandibular reconstruction-requirements and limitations. In Vivo 25: 795-799, 2011.

57. Warnke PH, Wiltfang J, Springer I, Acil Y, Bolte H, Kosmahl M, Russo PA, Sherry E, Lützen U, Wolfart S and Terheyden H: Man as living bioreactor: Fate of an exogenously prepared customized tissue-engineered mandible. Biomaterials 27: 3163-3167, 2006.

58. Moura LB, Carvalho PH, Xavier CB, Post LK, Torriani MA, Santagata $M$ and Chagas Júnior OL: Autogenous non-vascularized bone graft in segmental mandibular reconstruction: A systematic review. Int J Oral Maxillofac Surg 45: 1388-1394, 2016.

59. Mericli AF, Boukovalas S, Rhines LD, Adelman DM, Hanasono MM and Chang EI: Free Fibula Flap for Restoration of Spinal Stability after Oncologic Vertebrectomy Is Predictive of Bony Union. Plast Reconstr Surg 145: 219-229, 2020. 
60. Rao Janardhan S, Kotrashetti SM, Lingaraj JB, Pinto PX Keluskar KM, Jain S, Sone P and Rao S: Anterior segmental distraction osteogenesis in the hypoplastic cleft maxilla: Report of five cases. Sultan Qaboos Univ Med J 13: 454-459, 2013.

61. Wu V, Helder MN, Bravenboer N, Ten Bruggenkate CM, Jin J, Klein-Nulend $\mathbf{J}$ and Schulten EAJM: Bone tissue regeneration in the oral and maxillofacial region: A review on the application of stem cells and new strategies to improve vascularization. Stem Cells Int 2019: 6279721, 2019.

62. Vidal L, Kampleitner C, Brennan MA, Hoornaert A and Layrolle P: Reconstruction of large skeletal defects: Current clinical therapeutic strategies and future directions using 3D Printing. Front Bioeng Biotechnol 8: 61, 2020.

63. Wang MM, Flores RL, Witek L, Torroni A, Ibrahim A, Wang Z, Liss HA, Cronstein BN, Lopez CD, Maliha SG and Coelho PG: Dipyridamole-loaded 3D-printed bioceramic scaffolds stimulate pediatric bone regeneration in vivo without disruption of craniofacial growth through facial maturity. Sci Rep 9: 18439, 2019.

64. Hidalgo DA: Fibula free flap: A new method of mandible reconstruction. Plast Reconstr Surg 84: 71-79, 1989.

65. Byun SH, Lim HK, Yang BE, Kim SM and Lee JH: Delayed reconstruction of palatomaxillary defect using fibula free flap. J Clin Med 9: 884, 2020.

66. Hashemi S, Oda M, Onoue K, Basa K, Rubin SJ, Sakai O, Salama A and Ezzat WH: Determining the optimal osteotomy distance with the fibula free flap in mandibular reconstruction. Am J Otolaryngol: 41: 102436, 2020.

67. Lonie S, Herle P, Paddle A, Pradhan N, Birch T and Shayan R: Mandibular reconstruction: Meta-analysis of iliac-versus fibula-free flaps. ANZ J Surg 86: 337-342, 2016.

68. Iamaguchi RB, de Moraes MA, Silva GB, Cho AB, Iwase FDC, Wei TH, de Rezende MR and Mattar R Jr: Is obesity a risk factor for free vascularized fibular flap complications? Acta Ortop Bras 27: 192-196, 2019.

69. Prevost R, Kimakhe J, Diep D, Drouet J, Benateau H and Veyssiere A: The significance of computer-assisted surgery in avoiding double-barrel fibula grafts in reconstruction of the horizontal mandibular ramus. J Stomatol Oral Maxillofac Surg 120: 167-171, 2019.

70. Bartaire E, Mouawad F, Mallet Y, Milet P, El Bedoui S, Ton Van J, Chevalier D and Lefebvre JL: Morphologic assessment of mandibular reconstruction by free fibula flap and donor-site functional impairment in a series of 23 patients. Eur Ann Otorhinolaryngol Head Neck Dis 129: 230-237, 2012.

71. Vedakumari WS, Ayaz N, Karthick AS, Senthil R and Sastry TP Quercetin impregnated chitosan-fibrin composite scaffolds as potential wound dressing materials-Fabrication, characterization and in vivo analysis. Eur J Pharm Sci 97: 106-112, 2017.
72. Zhao W, Li Y, Zhou A, Chen X, Li K, Chen S, Qiao B and Jiang D: Controlled release of basic fibroblast growth factor from a peptide biomaterial for bone regeneration. R Soc Open Sci 7: 191830, 2020.

73. Yuan X, Xuan M, Tian W and Long J: Application of digital surgical guides in mandibular resection and reconstruction with fibula flaps. Int J Oral Maxillofac Surg 45: 1406-1409, 2016.

74. Foley BD, Thayer WP, Honeybrook A, McKenna S and Press S: Mandibular reconstruction using computer-aided design and computer-aided manufacturing: An analysis of surgical results. J Oral Maxillofac Surg 71: e111-e119, 2013.

75. Pattanayak DK, Fukuda A, Matsushita T, Takemoto M, Fujibayashi S, Sasaki K, Nishida N, Nakamura T and Kokubo T: Bioactive $\mathrm{Ti}$ metal analogous to human cancellous bone: Fabrication by selective laser melting and chemical treatments. Acta Biomater 7: 1398-1406, 2011.

76. Jia ZJ, Li M, Xiu P, Xu X, Cheng Y, Zheng Y, Xi T, Wei S and Liu Z: A novel cytocompatible, hierarchical porous Ti6Al4V scaffold with immobilized silver nanoparticles. Mater Lett 157: 143-146, 2015.

77. Bertollo N, Da Assuncao R, Hancock NJ, Lau A and Walsh WR: Influence of electron beam melting manufactured implants on ingrowth and shear strength in an ovine model. J Arthroplasty 27: 1429-1436, 2012

78. Azuma M, Yanagawa T, Ishibashi-Kanno N, Uchida F, Ito T, Yamagata K, Hasegawa S, Sasaki K, Adachi K, Tabuchi K, Sekido M and Bukawa $\mathrm{H}$ : Mandibular reconstruction using plates prebent to fit rapid prototyping 3-dimensional printing models ameliorates contour deformity. Head Face Med 10: 45, 2014.

79. Crafts TD, Ellsperman SE, Wannemuehler TJ, Bellicchi TD, Shipchandler TZ and Mantravadi AV: Three-dimensional printing and its applications in otorhinolaryngology-head and neck surgery. Otolaryngol Head Neck Surg 156: 999-1010, 2017.

80. Sweed AH, Bolzoni AR, Kadubiec A, Beltramini GA, Cherchi A and $\mathrm{Baj} \mathrm{A}$ : Factors influencing CAD/CAM accuracy in fibula free flap mandibular reconstruction. Acta Otorhinolaryngol Ital 40: 138-143, 2020

81. Friedli L, Kloukos D, Kanavakis G, Halazonetis D and Gkantidis N: The effect of threshold level on bone segmentation of cranial base structures from CT and CBCT images. Sci Rep 10: 7361, 2020.

This work is licensed under a Creative Commons Attribution-NonCommercial-NoDerivatives 4.0 International (CC BY-NC-ND 4.0) License. 